\title{
The Activities of Zeolite Catalysts for the Reaction of Aromatic Hydrocarbons*
}

\author{
Hiroshige Matsumoto** and Yoshiro Morita**
}

\begin{abstract}
Summary: The transformations of o-xylene and toluene on synthetic zeolite- $X$ catalysts containing $C a, C d, L a$ and $C e$ cations were investigated in the temperature range of 300 to $550^{\circ} \mathrm{C}$. The zeolite catalysts had high activities for both isomerization and disproportionation, which could be treated as the first order reaction. In the latter reaction zeolites showed the period of activation, which was decreased with increase of reaction temperature and with addition of a proton donor, such as hydrogen chloride or water.

The proton donor reversively promoted the catalytic activity of zeolite and enhanced the reaction rate proportionately to the amount of the adsorbate. From these observations, the active sites of the zeolite catalyst are formed by the interaction between the zeoliticc cation and the proton donor.
\end{abstract}

\section{Introduction}

As solid acid catalysts for the reactions of petroleum hydrocarbons, synthetic zeolites offer an ideal material both for fundamental studies and for industries. Zeolite- $\mathrm{X}$ has a well-defined crysta] structure with a uniform pore size of molecular dimension. Furthermore, an exchanging of metal cation in the structure with other cation considerably replaces the catalytic properties of zeolite. However, there seems to be a little investigation of zeolite catalyst in isomerization and disproportionation of aromatic hydrocarbons, while many studies are carried out in cumene cracking. In this work, activity test of zeolite catalyst for these reactions were carried out using a flow apparatus under atmospheric pressure. The promotive effects of the proton donor, such as hydrogen chloride or water, were also studied in the catalytic systems of zeolite, alumina, and silica-alumina to consider the nature of active centers for the reactions.

\section{Experimental}

\section{(1) Apparatus and Procedure}

The apparatus used for the reactions of 0 -xylene and toluene is shown schematically in Fig. 1. The carrier gas (hydrogen) from high-pressure cylinder was passed through a purification train of $\mathrm{Pd}$ and Molecular Sieve $13 \mathrm{X}$ to remove oxygen

* Received November 8, 1967

* * Department of Applicd Chemistry, Waseda University (4-170, Nihis-okubo, Shinjuku-ku, Tokyo, Japan)

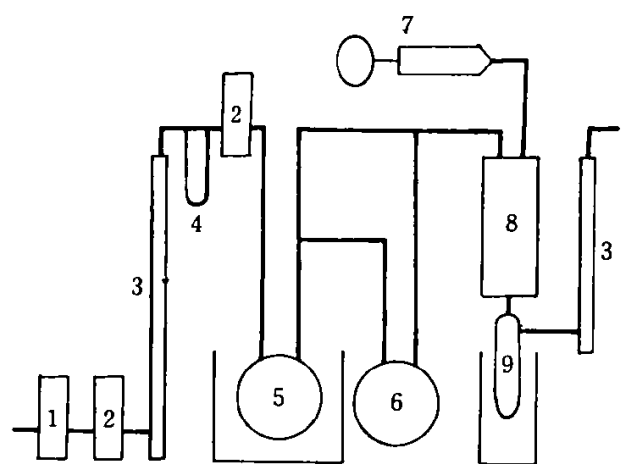

Fig. 1 Schematic Diagram of Reaction Apparatus 1. Deoxygenator 2. Dehydrator 3. Flow meter 4. Manometer 5. Vapor Saturator 6. $\mathrm{H}_{2} \mathrm{SO}_{4}$ bath
7. Feeder
8. Reactor
9. Product-Receiver

and water contaminants. The reaction tube was a $23 \mathrm{~cm}$ diameter silica tube of $60 \mathrm{~cm}$ long with a constriction near the middle to hold a catalyst basket. Two tubular furnaces were fixed around the silica tube to preheat and heat the gas mixture up to the required temperature. The hydrocarbons were pumped at a constant rate from a gas-tight syringe drived with a synchronous motor. The molar ratio of hydrogen/hydrocarbon was 3.6 in all cases. Eight $g$ of a catalyst was calcined at $450-500^{\circ} \mathrm{C}$ for $2 \mathrm{hrs}$. and then treated at the reaction temperature by hydrogen gas prior to charging feed until the constant temperature was obtained.

In the addition of hydrogen chloride to the reaction system, the carrier gas was bubbled through the hydrochloric acid solution of desired concentration, which was immersed in a constant- 
temperature bath. The carrier gas saturated with a suitable portion of hydrogen chloride was conducted to $\mathrm{H}_{2} \mathrm{SO}_{4}$ bath to remove water. The effect of $\mathrm{H}_{2} \mathrm{SO}_{4}$ vapor to catalytic activity was negligible in the similar condition. The method of the water addition to the system was as same as that of hydrogen chloride without bubbling in the $\mathrm{H}_{2} \mathrm{SO}_{4}$ bath. The amount of hydrogen chloride adsrobed over a zeolite was measured with a conventional pyrex system at $300^{\circ} \mathrm{C}$.

The analysis of liquid product was carried out by gas chromatography (column: Bentone-34) and gaseous product was not determined, because it consisted of only traces of methane.

(2) Catalysts and Materials

The zeolite catalysts used in this work were prepared by ion-exchanging Linde, $13 \mathrm{X}$ with 0.05-0.10 mole metal nitrate or metal chloride aqueous solutions. The remaining sodium ion contents of the zeolite prepared were ranged from 30 to $50 \%$. Amorphous silica-alumina was an F.C.C. catalyst (alumina content, $23 \%$ ) provided from Nippon Oil Co., alumina was of high purity from Nippon Keikinzoku Co. and silica was prepared by the gelation of sodium silicate with hydrochloric acid.

Commercial GR grade toluene and $o$-xylene were dehydrated with metallic sodium, distilled and passed through silica gel column. Hydrochloric acid was GR grade without any treatment.

(3) Arrangement of Reaction Product

It was thought that the three kinds of reaction (isomerization, disproportionation and dealkylation) proceeded in the condition studied; as for toluene, $m$ - and $p$-xylenes, 1,2,3- 1,2,4and 1,3,5-trimethylbenzenes were observed in the liquid products of $o$-xylene reaction. On that account, the yields of these reactions were determined as follows;

1) Isomerization $(\mathrm{Ix})=\frac{\mathrm{m}-\mathrm{X}+\mathrm{p}-\mathrm{X}}{\mathrm{F}}$

2) Disproportionation $(\mathrm{Dx})=\frac{2 \mathrm{TMB}}{\mathrm{F}}$

3) Dealkylation $(\mathrm{Cx})=\frac{\mathrm{T}-\mathrm{TMB}}{\mathrm{F}}$

where, $X, T M B$ and $T$ represent moles of xylene, trimethylbenzene and toluene in the reaction product, respectively, and $F$ is that of feed charged to the system.

In the case of toluene reaction, the yield was similarly determined as follows;

$$
\begin{aligned}
\mathrm{DT} & =\frac{2 \mathrm{X}}{\mathrm{F}} \\
\mathrm{C} \mathrm{T} & =\frac{\mathrm{B}-\mathrm{X}}{\mathrm{F}}
\end{aligned}
$$

where $B$, represents mole of benzene in th product. Experimental Results and Interpretation (1) Reactions of o-Xylene and Toluene on Zeolite Judging from the product distribution, it was thought that the three types of reactions; isomerization, disproportionation and dealkylation proceeded in the reaction of $o$-xylene catalyzed by zeolite (Fig. 2). This phenomenon was observed also with aluminium chloride catalyst. ${ }^{1)}$ The dealkylation was prevented under a mild reaction

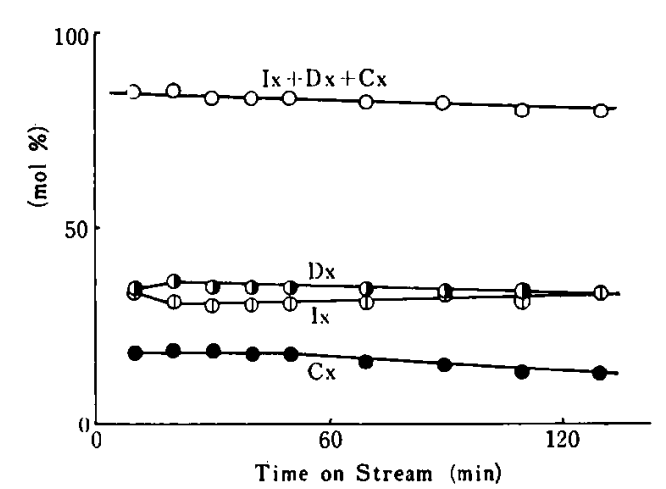

Fig. 2 Reaction Product of $o$-Xylene on $\operatorname{LaX}\left(500^{\circ} \mathrm{C}\right.$, $\mathrm{LHSV}=1 \mathrm{hr}^{-1}$ )

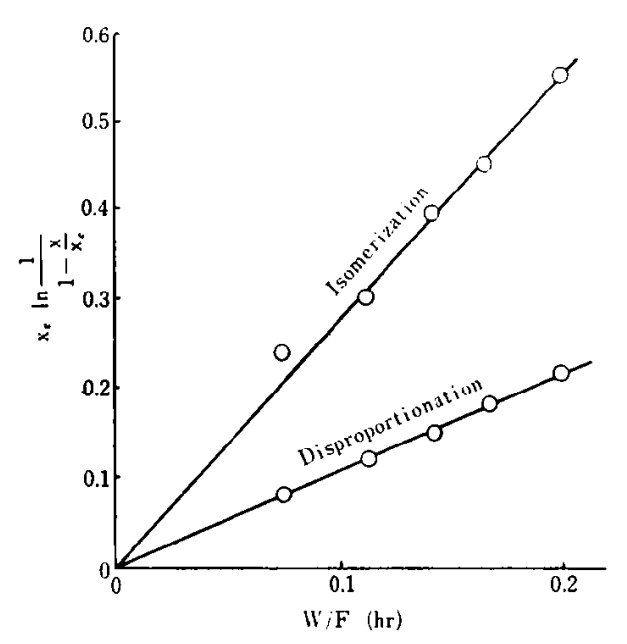

Fig. 3 Pseudo-First Order Plots of $o$-Xylene Reaction on $\mathrm{CeX}$ at $400^{\circ} \mathrm{C}$

condition, so only remaining two reactions were expressed kinetically. A linear relationship was observed between $-\mathrm{Xe} \ln [1-(\mathrm{X} / \mathrm{Ne})]$ and $\mathrm{W} / \mathrm{F}$ as shown in Fig. 3, where $\mathrm{X}$ and $\mathrm{Xe}, \mathrm{W}$ and $\mathrm{F}$ are the observed and equilibrium fractional conversion, weight of catalyst $(\mathrm{g})$ and charge rate of 0 -xylene 
$(\mathrm{g} / \mathrm{hr})$. respectively. The isomerization and disproportionation of $o$-xylene, therefore, could be independently treated as the pseudo-first order reaction.

The typical reaction of toluene orer zeolite was similarly consistent with disproportionation and delakylation as presented in Fig. 4, namely, the value $\mathrm{B} / \mathrm{A}$ was above unity. It was a distinctive feature in this reaction that the zeolite catalyst had some period to be activated. On the other hand, conventional silica-alumina catalyst did not show this period. The existence of the period of activation was, therefore, a

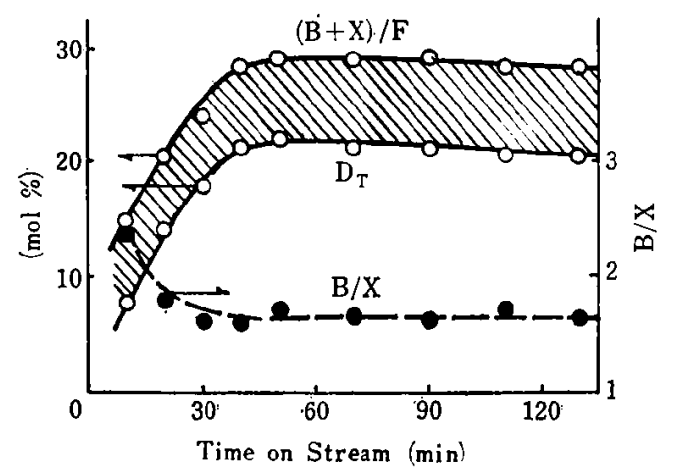

Fig. 4 Reaction Production of Tolvene on CaX $\left(550^{\circ} \mathrm{C}, \quad \mathrm{LHSV}=1 \mathrm{hr}^{-1}\right)$,

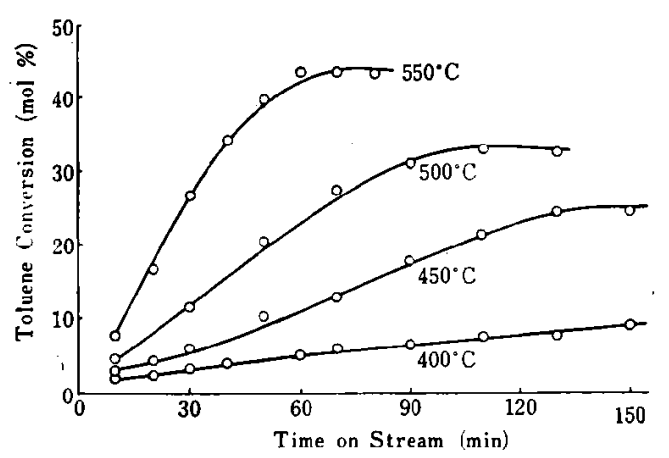

Fig. 5 Effect of Reaction Temperature for Tolvene on $\mathrm{LaX} \quad\left(\mathrm{LHSV}=1 \quad \mathrm{hr}^{-1} \quad \mathrm{P}_{\mathrm{H}_{2} \mathrm{O}}=2.9 \%\right)$

characteristic of zeolite catalyst in the disproportionation reaction. This period was, furthermore, reduced with the increase of the reaction temperature (Fig. 5). Similar reductions of these periods with temperature were also observed in the systems of $\mathrm{CaX}, \mathrm{CdX}$ and $\mathrm{CeX}$.

(2) Activity of the Zeolite Catalyst

The observed activities for the reaction of $o$ xylene with the calcium zeolite, cerium zeolite and conventional silica-alumina catalyst were compared in Fig. 6. The activity of Cex exceeded that of the conventional catalyst in all temperature

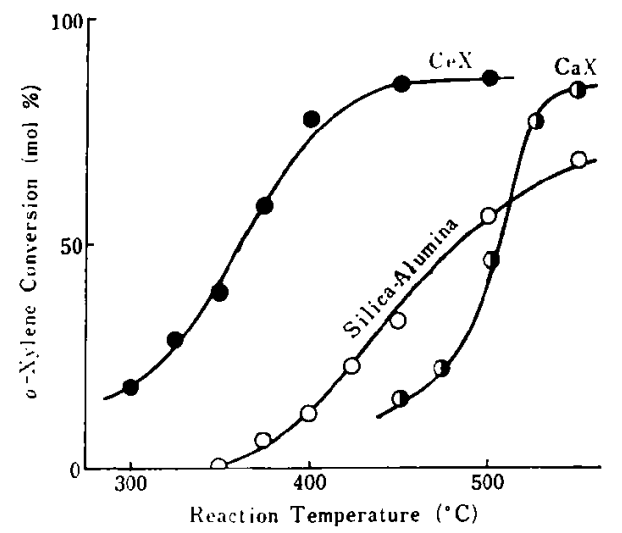

Fig. 6 Activities of Zeolites and Conventional Catalyst for 0 -Xylene Reaction $\left(\mathrm{LHSV}=1 \mathrm{hr}^{-1}\right.$ )

range tested, while $\mathrm{CaX}$ showed high conversion only at the higher reaction temperature. The activities of $\mathrm{LaX}$ and other divalent cation zeolites (CdX, $\operatorname{MgX})$ for the $o$-xylene reaction had strong resemblance to those of $\mathrm{CeX}$ and $\mathrm{CaX}$, respectively.

There was a great difference between the product distributions with zeolite and silicaalumina as shown in Fig. 7. In the reaction of $o$ xylene the zeolite catalyst had considerable

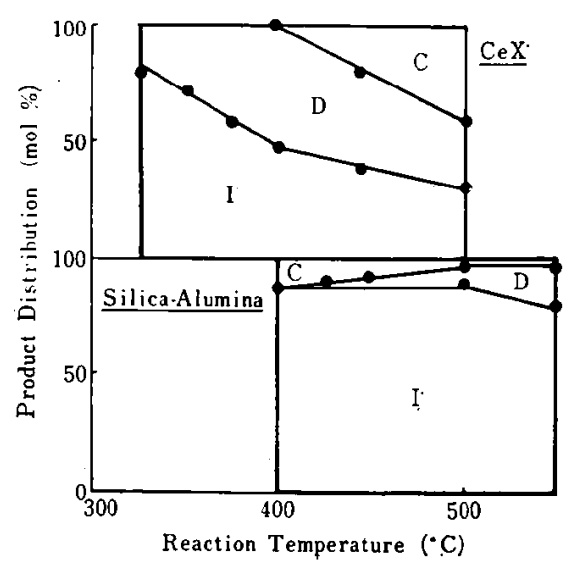

Fig. 7 Product Distribution of $o$-Xylene Reaction on $\mathrm{CeX}$ and Silica-Alumina $\left(\mathrm{LHSV}=1 \mathrm{hr}^{-1}\right)$

I; Isomerization product $\quad \mathrm{D}$; Disproportionation product C; Dealkylation product

activities for both disproportionation and dealkylation in addition to isomerization above $400^{\circ} \mathrm{C}$, however, conventional silica-alumina catalyst promoted isomerization selectively. With the increase of the reaction temperature and of the contact time in the zeolite system, the ratio of the isomerization products, $m$-xylene/ $p$-xylene was decreased (Fig. 8). And the observed fractional concentrations of $m$ - and $p$ xylene were identical with the equilibrium values, 


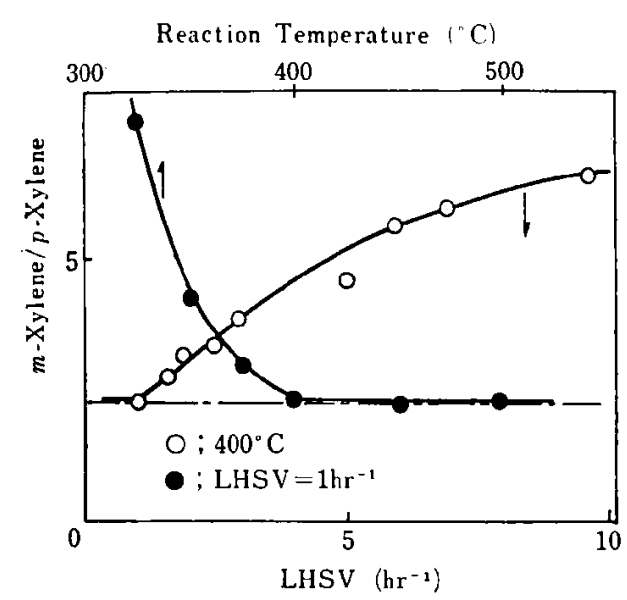

Fig. 8 Isomerization Product of $o$-Xylene on CeX

when the reaction was carried out above $400^{\circ} \mathrm{C}$ $\left(\mathrm{LHSV}=1\right.$ ) or below LHSV $=1$ (at $400^{\circ} \mathrm{C}$ ). These facts may explain that the isomerization of $o$-xylene to $p$-xylene is proceded by the isomerization to $m$-xylene (namely, migration of methyl group along aromatic ring).

The activities of zeclite catalysts and silicaalumina catalyst for toluene conversion are shown in Fig. 9. In all temperature range experimented, the activities of $\mathrm{LaX}$ and $\mathrm{CdX}$ were predominant in comparison with that of silica-alumina. The $\mathrm{B} / \mathrm{A}$ value with zeolite catalysts rapidly increased with the increase of the reaction temperature, while this value

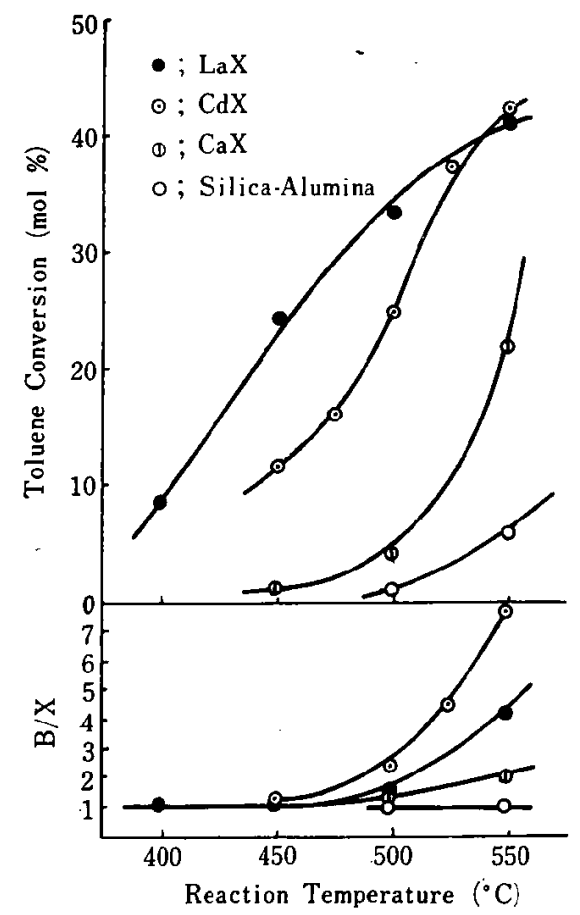

Fig. 9 Activities of Zeolites and Convertinal 'Catalyst ( $\mathrm{LHSV}=1 \mathrm{hr}^{-1} \mathrm{P}_{\mathrm{H}_{2} \mathrm{O}}=2.9 \%$ ) with silica-alumina was equal to unity even at $550^{\circ} \mathrm{C}$ (Fig. 9).

On the other hand, $\mathrm{NaX}$ (Linde 13X) was completely inactive for these reactions carried out under the similar conditions.

(3) Introduction of Proton Donor

Enhancement of conversion or reduction of the period of activation upon introduction of a proton donor to the catalysis system strongly suggests a role of protons in the reaction. Such a promotive effect was shown for the toluene reaction, when $3 \%$ of hydrogen chloride or water was added in the carrier gas (Fig. 10). In the

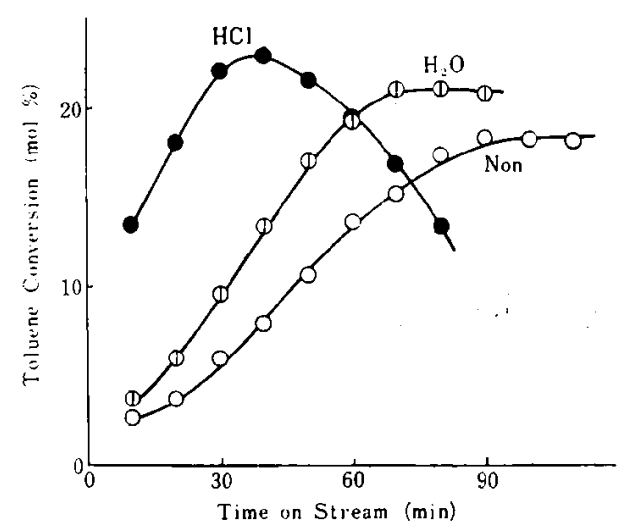

Fig. 10 Effect of $\mathrm{HCl}$ and $\mathrm{H}_{2} \mathrm{O}$ introduction for Toluene reaction $\left(\mathrm{LaX} . \mathrm{LHSV}=1 \mathrm{hr}^{-1}, \mathrm{PHCl}_{1}, \mathrm{P}_{\mathrm{H}_{2} \mathrm{O}}=\right.$ 2.9\%)

addition of hydrogen chloride, the period of activation was shrotened, with subsequent decrease of the conversion with time. This decrease of activity would be resulted from the blocking of active sites by localized carbonaceous matter which was formed in the suitable condition.

Similar promotive effects of hydrogen chloride were observed in the o-xylene reaction. This effect and its reversibility for the catalysts of $\mathrm{LaX}$, silica-alumina, silica and alumina were investigated (Fig. 11). The promotive effect of hydrogen chloride for zeolite was reversible and more remarkable than that for silica-alumina. On the other hand, hydrogen chloride considerably accelerated the activity of alumina at high temperature, but the enhanced conversion did not fall to the level before the treatment. Before and after the treatment with hydrogen chloride, activity of silica was not changed.

If it could be postulated that the action of hydrogen chloride for zeolite contribute to the formation of active Brönsted acid, a direct 


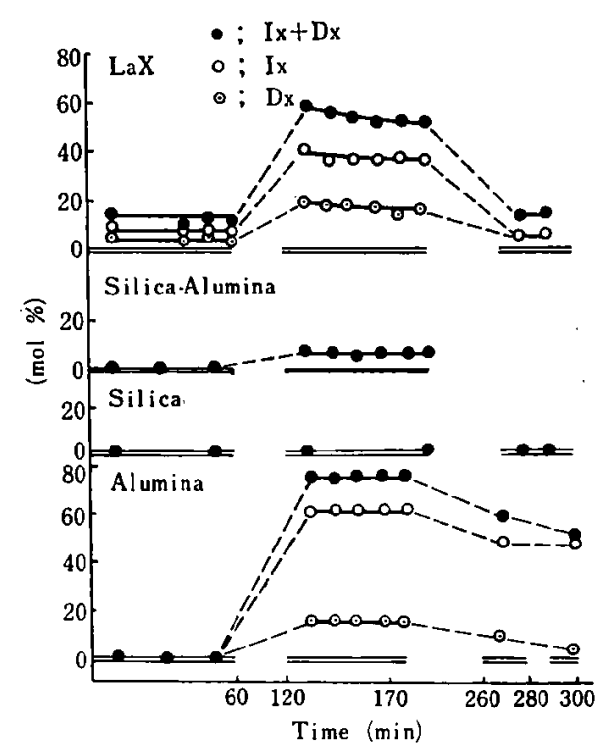

Fig. 11. Effect of $\mathrm{HCl}$ Introduction for $o$-Xylene reaction

LaX; $325^{\circ} \mathrm{C}, \mathrm{PHCl}_{\mathrm{HCl}}=91 \mathrm{mmHg}$

Silica-alumina; $350^{\circ} \mathrm{C}, \mathrm{PHCl}_{\mathrm{H}}=91 \mathrm{mmHg}$

Silica and alumina; $500^{\circ} \mathrm{C}, \mathrm{PHCl}_{\mathrm{H}}=52 \mathrm{mmHg}$

$=$; Under $\mathrm{HCl}$ stream

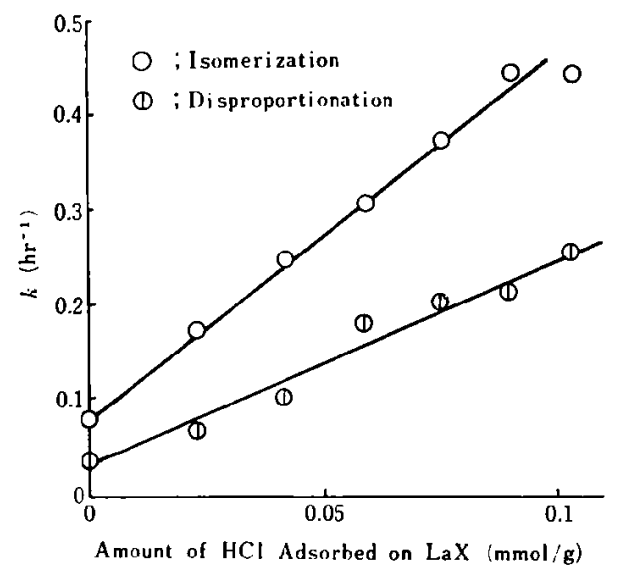

Fig. 12 Contribution of $\mathrm{HCl}$ for Acfivity of zeolite. $\left(300^{\circ} \mathrm{C}, \mathrm{LHSV}=1 \mathrm{hr}^{-1}\right)$

relationship is expected between the activities and the amounts of the hydrogen chloride adsorbed on the surface. Now, the amount of the hydrogen chloride absorbed on $\mathrm{LaX}$ was measured at $300^{\circ} \mathrm{C}$ under various partial pressures. Furthermore, the activities of isomerization and disproportionation of 0 -xylene were tested at the same temperature in the pressures of hydrogen chloride. These results were shown in Fig. 12. The rates of the both reactions were found to have linear relation with the amounts of adsorbed hydrogen chloride.

\section{Discussion}

A considerable enhancement in the reaction rate was observed upon introduction of a proton donor, and alumina (consisting of Lewis acid) was inactive even at high temperature. These evidences are consistent with the idea that the active sites of the catalyst for the reaction of $o$-xylene or toluene are Brönsted acid. The activity enhancement, however, cannot be resulted from the catalytic action of hydrogen chloride itself. This reason is that silica was completely inactive in the addition of hydrogen chloride even at the high temperature (Fig. 11).

It is attended with danger to consider that hydrogen chloride promote both zeolite and alumina in an identical manner, though considerable enhancements were observed in the both systems. It was reported ${ }^{2}$ that catalytic activity of alumina or silica-alumina catalyst was promoted by a treatment with halogen compounds. This phenomenon seemed to be resulted from an exchange of a halogen atom with an oxygen atom or a hydroxide group on the surface ${ }^{3}$, namely from the increase of inductive effect. This consideration is consistent with the fact that hydrogen chloride irreversibly enhances the activity of alumina catalyst (Fig. 11).

In the reaction over zeolite catalyst, the promotive action of hydrogen chloride was reversible (Fig. 11), so it is unreasonable to consider that the chlorine atom of hydrogen chloride is exchanged with the oxygen atom in the framework of zeolite. (1) Hydrogen chloride, therefore, seems to interact with the zeolitic cation. Furthermore, from the linear relationship between the activity and the amount of adsorbed hydrogen chloride on zeolite (Fig. 12), (2) the active sites of zeolite may be formed with the adsorption of hydrogen chloride. As described in many works, (3) the sites active for aromatic hydrocarbons are protonic acid. From these considerations, the active centers of zeolite catalyst may be formed by reversible interaction between hydrogen chloride and zeolitic cation, as follows;

$$
\mathrm{Me}^{+} \mathrm{Z}^{-}+\mathrm{HCl} \rightleftharpoons \mathrm{Me}^{\delta+} \mathrm{Z}^{-}
$$

where $\mathrm{Me}^{+}$(zeolitic cation) is generally polyvalent and its residual positive valencies are neutralized with the negative valencies of the framework, $Z$.

Water molecule probably interacts with zeolitic cation analogously to hydrogen chloride, although its promotive effect is small (Fig. 10). 


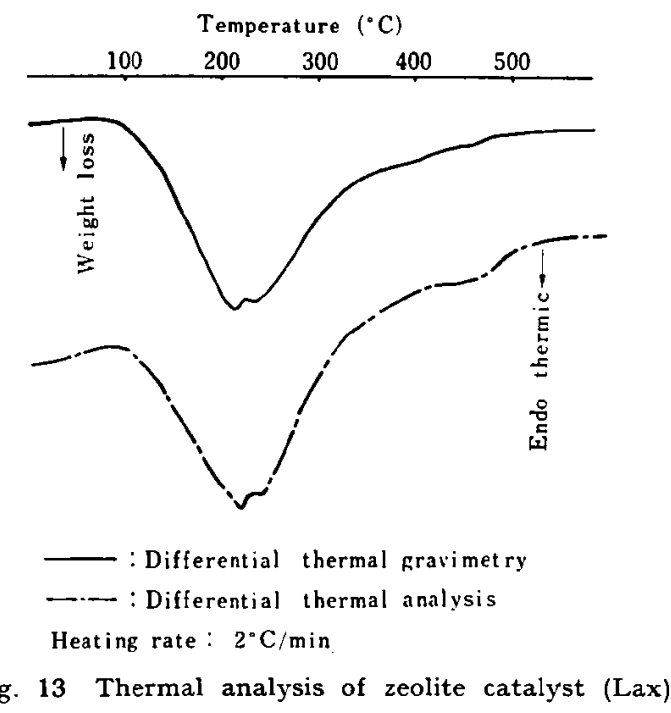

And the zeolite adsorbed small amount of water at the calcination temperature, $400-500{ }^{\circ} \mathrm{C}$, (Fig. 13). From these reasons, it is reasonable that considerable activities of the zeolite catalysts were observed in the absence of hydrogen chloride (Fig. 6, Fig. 12). The activity enhancement of zeolite catalyst with water has been recogznied in other works ${ }^{4), 5}$ ), where activity of zeolite catalyst is decreased with increase of the pretreatment temperature.

Though it is still obscure why zeolite catalyst is remarkably active for the disproportionation of alkylbenzenes in comparison with amorphous silica-alumina, it may involve considerations from two angles. The first, zeolite has a high density of active sites (an acidity of zeolite was 2-10 times as large as that of amorphous aluminosilicate), so that a strong interaction between two adsrobed molecules is expected (Hinshelwood mechanism.) The second, the pore structure of zeolite (molecular dimension) is suitable for an interaction between adsorbed molecule and molecule in the gas phase (Redeal mechanism).

\section{Conclusion}

1) In the reaction of $o$-xylene, zeolite catalyst promoted isomerization and disproportionation and these reactions could be treated as pseudofirst order kinetics.

2) In the reaction of toluene, zeolite catalyst showed peculiar period of activation, which decreased with the increase of reaction temperature.

3) Zeolite catalyst containing cadmium or rareearth cation had high activity for the both reactions in comparison with amorphous silicaalumina catalyst.

4) In an addition of proton donor to zeolite, the activity was increased and the period of activation was reduced.

5) The promotion effect of hydrogen chloride was reversible and proportional to the amount of the adsorbate.

6) The active sites of zeolite catalyst are probably formed by the interaction between zeolitic cation and proton donor.

\section{Peferences}

1) Allen, R.H. et al., $J . A m$. Chem. Soc., 81, 5289 (1959); ibid., 82, 4853 (1960).

2) Echigoya, E., Thesis of Tokyo Inst. Technol. (1957).

3) Gerberich, H.R., Lutinski, E.F., Hall, W.K., $J$. Catalysis, 6, 209 (1966).

4) Yamamoto N., Fujii, K., Idemaru, Y., Furukawa, T., Bull. Japan Petrol. Inst., 8, 13 (1966).

5) Venuto P.B., Hamilton L.A. Landis, P.S., Weise, J.J., J. Catalysis, 5, 81 (1966). 